\title{
Long-term energy services security: What is it and how can it be measured and valued?
}

\author{
Jaap C. Jansen *, Ad J. Seebregts \\ Energy research Centre of the Netherlands (ECN), Petten, The Netherlands
}

\section{A R T I C L E I N F O}

\section{Article history:}

Received 9 February 2009

Accepted 13 February 2009

Available online 29 April 2009

\section{Keywords:}

Energy services security

Diversity-based indices

Supply/Demand Index

\begin{abstract}
A B S T R A C T
The paper reviews some recent approaches towards measuring the extent of long-term energy security and security externality valuation. It starts out to discuss the contextual connotations of notions of 'energy security' in medium to long-term time frames and reviews some indicators that have been proposed to quantify it. Special attention is paid to two of these approaches, which the authors helped to develop, i.e. diversity-based indices and the Supply/Demand Index. The paper takes issue with conventional welfare economic approaches that neglect: (i) the scope on the demand side for raising security and (ii) negative feedback mechanisms of socio-political impacts of international rent transfers in fossil fuels exporting countries. The concept of energy services security is proposed with a demandside focus. This enables application of an integrated approach to gauge the resilience of a society to meet the needs of its population for energy services over longer timescales ahead from various interrelated perspectives. Propositions are made on the attribution of security externalities to the use of fossil fuels, policies, and suggestions for further improvements of measures for energy services security. (c) 2009 Elsevier Ltd. All rights reserved.
\end{abstract}

\section{Introduction}

This paper sets out to provide some useful perspectives on the security for the population in a defined area to meet its needs for energy services over medium to long timescales. ${ }^{1}$ It discusses some recent approaches, and their respective underlying philosophy, to measure and enhance energy services security (ESS) with special reference to the European Union.

Conventional approaches to long-term 'energy security', especially economic modelling approaches, tend to zoom in - in part or at best in full - on the supply side of primary energy sources (PES) or energy carriers. They tend to focus on the supply of one or more of the exhaustible fuels: oil, natural gas, and/or coal (Bohi and Toman, 1996; Lefèvre, 2007). ${ }^{2}$ Based on the focus of

\footnotetext{
* Corresponding author. Tel.: +31022456 4437; fax: +31 0224568338.

E-mail address: j.jansen@ecn.nl (J.C. Jansen).

${ }^{1}$ This paper is partly based on Jansen et al. (2004) and Scheepers et al. (2006, 2007). The authors acknowledge the contribution made by Martin Scheepers (ECN), Jacques de Jong (CIEP) and Hans Maters (CIEP) to the design of the Supply/ Demand Index, the Dutch Ministry of Economic Affairs for financial support and two anonymous referees for helpful comments.

${ }^{2}$ Uranium is also exhaustible. In this short paper, we have refrained from considering the security issue for the nuclear option. Nuclear-power-specific issues (potential catastrophic accidents; proliferation of nuclear weapons technology; waste management) dominate the supply security of nuclear power and sustainability discussion regarding its deployment. Exhaustibility of uranium as well as carbon and regionally noxious emission impacts are of secondary importance in this regard. Scarcity of uranium is rather a matter of cost
}

these approaches, long-term "energy (supply) security" can be considered as a proxy of the certainty level at which the population in a defined area has uninterrupted access to fossil fuels and fossil-fuel based energy carriers in the absence of undue exposure to supply-side market power over a period ahead of 10 years or longer. This definition can be applied in a backward or forward-looking manner (yielding ex-post estimates or ex-ante projections, respectively) and puts the focus on the functioning of markets for fossil fuels and derived products. Special issues of attention are non-competitive pricing resulting from the exercise of market power by foreign fuel exporters, the subsequent adverse socio-economic implications for the defined population and the options, this population has to reduce its vulnerability to foreign fuel suppliers (capable of) exercising market power.

Ongoing liberalisation of EU and a range of other major energy markets have widened the range of actors that influence longterm supply risks for end users. Before the advent of liberalisation long-term energy security responsibility resided with the large

\section{(footnote continued)}

(to explore and develop conventional resources or to extract it from ambient unconventional sources) and resource-economizing technology development (e.g. Generation IV close cycle, including breeder reactor, technology). Depletion of ultimate reserves or the sustained ability to exercise market power by uranium producing countries would seem to have a quite modest upward impact on the cost of nuclear power in the foreseeable future relative to other cost factors, such as the evolution of plant construction cost. The modest role of fuel resource cost in the case of nuclear power stands in stark contrasts with gas-, oil- and, to a somewhat lesser extent, coal-based generation. 
multinational oil companies and mainly public companies in other energy domains. To date, the evolution of long-term energy security risks in major fuel-importing regions is determined by a multitude of private and public actors within those regions as well as extra-regional fuel suppliers with, typically, close links to the central government in their respective country of origin.

When energy security gets media or political attention, this is often brought about by emergency situations. Such events include: consumers suddenly facing physical shortages at the gas filling stations or following black-outs within the electricity supply system; consumers facing sudden energy price spikes; lorry drivers blocking motorways in protest of steep price rises of gasoil; etc. Looming risks to ESS on longer timescales do tend to attract less attention. On the other hand, enhancing societal resilience against long-term price (volatility) risks of energy services in the face of strong inertia in a national or regional energy system warrants sustained and coherent policy efforts.

Considering the above, there is a strong case to explore the long-term evolution of energy supply security and related externalities for policy design purposes. Suitable ESS indicators might provide information to policymakers and their constituencies on the seriousness of long-term overall supply risk. Moreover, political agreement may be reached that exceeding a priori agreed critical ESS values will trigger implementation of an agreed set of emergency procedures to mitigate energy services security. In addition, rising awareness of perceived strong supply security externalities among high-profile NGOs and the wider electorate may trigger policymakers to make public interventions to internalise these into market prices and the cost-benefit analyses of long-term energy security enhancing measures.

Section 2 proposes a general approach to the measurement of energy services security. Some general issues regarding the valuation of the supply security externality are discussed in Section 3. Section 4 reviews some recent approaches to the measurement of 'energy security'. Mainstream approaches, adopted to the valuation of security externalities, are addressed in Section 5. Section 6 winds up this paper with concluding methodology and policy observations.

\section{How secure is an energy economy?}

In this section we will explain the following propositions:

- Curbing the use of fossil fuels, in a socio-economically efficient way over longer timescales, is the main lever towards achieving a more secure energy economy.

- A demand-side focus is warranted to enhance the resilience level of a defined population in facing vulnerabilities to its access to energy services on long timescales.

- A credible index to gauge medium/long-term energy services security of a defined population strikes a good balance between measuring demand-side resilience against energy services security vulnerability and the magnitude of the energy services security vulnerability itself.

- Both the scale factor of supply, conversion and transport infrastructure and length of supply chains appear to be inversely related to energy services security.

\subsection{Towards a more secure energy economy}

A key question of how to achieve a secure energy economy on longer timescales is: how can the population in a defined area achieve, at lowest long-term social cost, an acceptable level of certainty of meeting its needs for end-use energy services? ${ }^{3}$ In assessing this question, a given level and distribution of overall living standards and compliance with given standards for environmental impacts are points of departure. The insecurity related long-term social cost would be in terms of reduction in overall material living standards, increase in global socioeconomic inequity and/or an increase in environmental cost.

In the current energy economy of the economically advanced countries, end-use energy services are mainly energized - directly or indirectly - by oil, natural gas, and coal. In addition, oil and natural gas are major inputs for industrial feedstock for commodities such as plastic products and fertilizers. Although oil, natural gas, and coal each have their own specificities, some general tendencies hold true. For these exhaustible resources in high demand, a natural tendency exists for their supply chains to demand centres to get longer as time goes by. Furthermore, along with rising supply-side market concentration major consumer markets get more prone to supply vulnerabilities including the exercise of monopolistic market power by major exporters. Moreover, under conditions of increasing tension between inelastic supply and inelastic demand, price volatility tends to increase as well. This is further driven by: social and political disturbances in exporting and, if to a lesser extent, importing countries (explained in Section 3 hereafter); damages to vital supply infrastructure facilities all along the supply routes as a result of technical failures, deliberate rebel or terrorist attacks or adverse weather events; and transport capacity constraints (Stern, 2002; Percebois, 2006). Moreover, use of fossil fuels has substantial environmental impacts. Hence, meeting useful, currently fossil-fuels-driven, energy services in alternative ways and reducing wasteful energy services can have significant net environmental benefits and net security benefits, depending on the characteristics of alternative services.

We postulate that curbing the use of fossil fuels - over longer timescales, to the maximum extent possible in a socio-economically efficient way - is most effective towards achieving a more secure energy economy. In assessing the long-term efficiency of phasing out the use of a fossil fuel, its differential impacts on overall living standards (national/regional income levels with due regard for social equity), environmental impacts and security vulnerability impacts of alternative end-use services have to be properly weighed.

\subsection{Enhancing resilience against energy services security vulnerability}

Let us coin the certainty level of enduring, uninterrupted access of the population in a defined region to affordably and competitively priced, environmentally acceptable energy end-use services by the term energy services security. This definition implies an end-use orientation to enable a genuinely integrated approach to this multi-facetted issue. The size and composition of demand for energy end-use services is driven by consumer income levels, lifestyles and associated consumer preferences as well as spatial and building infrastructures shaping living, working, and travel conditions of consuming and producing agents. To the extent that certain lifestyles give rise to high-environmental externalities, consumer behaviour is an essential part of the ESS problem.

For enhancing long-term energy services security, long-term externalities have to be curbed. Neglect of socio-political externalities will increase energy services insecurity for present

\footnotetext{
${ }^{3}$ End-use energy services include end-use functions of non-energy commodities that currently embody feedstock from fossil fuels.
} 
and, notably, future generations. The harmful externalities in a country may increasingly weaken a population's capacity to pay: in the absence of an expeditious, socio-economically efficient, phasing-out of fossil fuels, fossil fuel prices are set to rise to unaffordable levels. ${ }^{4}$ Moreover, lock-in inertia will raise the cost of a postponed transition towards genuinely sustainable energy services.

As a starter to a discussion on long-term energy services security, it is in order to take a closer look at the concept of 'energy security'. Walt Patterson observes that according to the first law of thermodynamics no single joule of energy gets lost. By implication nobody produces nor consumes energy and energy security is, strictly speaking, a non-issue (Patterson, 2007). The noun energy in 'energy security' refers to carriers of stored energy (such as fuels and derivatives) and electricity. This seems trivial but it is not. By and large, ambient energy is plentiful across the earth. Ambient energy (wind, solar, flow-of-the-river hydro, marine energy) can be used directly, converted directly into electricity or converted into a stored form of energy. Yet ambient forms of energy themselves cannot be possessed. Hence, its use as such does not bring about resource rent transfers. To a lesser extent, this also holds for regenerative biomass resources. ${ }^{5}$

Trade-offs exist between decentralised, localised provision of energy services based on renewable energy sources and centralised provision of energy services based on fossil fuels and nuclear energy. In the advanced economies technological development has capitalised on the economics of scale that can be achieved in extracting and using high density but exhaustible fuels for a range of applications, including importantly centralised high-voltage electricity generation. However, supply chains to demand centres tend to get longer and market concentration on the supply side stronger. This implies that from a certain point onwards increasing supply chain vulnerabilities emerge. Likewise, centralised power grid management gets disproportionately more complex by the ascent of decentralised generation. Unless properly managed at high cost, risks of deteriorating service levels rise up to levels where the risk of black-outs cascading across large areas cannot be fully discounted. ${ }^{6}$

On the other hand, amply available ambient energy resources are as such free-of-charge. For a range of direct thermal applications the costs to harness ambient energy are already competitively low (e.g. passive solar space heating and cooling). The cost of typically quite expensive decentralised generation equipment harnessing ambient energy sources tend to come down and technical performance improves through rapid technological learning. Moreover, efficient use of small-scale distributed energy resources warrants active network management, involving all system components including notably the end users. This, in turn, tends to render demand appreciably more price elastic. All in all, a gradual shift in the economics from centralised, large-scale towards decentralised, small-scale provision of energy services is occurring. Acceleration of this trend in a socioeconomically efficient way appears warranted to enhance long-term EES.

\footnotetext{
${ }^{4}$ Average extraction costs are set to rise exponentially and market concentration likewise. Climate change and adaptation cost may assume catastrophic levels.

${ }^{5}$ Regarding ambient energy sources locational rents at attractive sites occur, especially for installation of high-capacity equipment to harness energy from such sources. If and when such rents take large proportions, such rents can also become a significant externality. Given the relatively good spread of ambient energy sources across the earth, this issue compared to the resource rent issue would seem to remain very small.

${ }^{6}$ See Patterson (2007). For instance, in August 2003 a large cascading blackout happened in the US Northeast and Midwest and Canada with an immediate shut down of 21 nuclear reactors. This blackout affected at least some 50 million people.
}

\section{Security externality valuation: general statements}

In this section we set out the following propositions:

- The use of fossil fuels carries substantial but uncertain external ESS costs.

- A widely neglected key factor is the appropriation of resource rents associated with the use of fossil fuels: its size; concentrated incidence; vicious impact on the emergence of predatory states with rent-seeking behaviour within the public and private sectors of many fuel-exporting countries (Karl, 1997); and, last but not least, its socio-political and economic backlash on fuel-importing countries.

- No positivist, value-neutral approach exists to quantitatively project the external security cost in a robust way.

\subsection{Externalities to the use of fossil fuels}

Oil supply vulnerabilities are well known whilst common wisdom has it that supply vulnerabilities regarding the coal supply chain are rather modest. The natural gas market is a highly concentrated suppliers market, which is boosted by the increasing environmental premium natural gas commands and the surging demand for flexible power generation capacity. Increasing concentration on the supply side makes for rapidly swelling vulnerabilities to major gas consuming countries. Under these conditions the share of LNG in international gas trade increases the bargaining position of gas exporters as they get more flexibility to shift part of their exports to extra-regional buyers. But even for coal supply vulnerabilities increase along with an increasing ratio of world coal trade to world coal consumption, rapidly declining global $R / P$ ratios and, importantly, increasing market concentration on the exporting side (IEA, 2007; Lefèvre, 2007). Moreover, the transport margin makes up a significant component of the price of delivered coal in coal importing countries, whilst this margin is susceptible to the vagaries of the boom-and-bust cycles in bulk sea freight transportation sector.

The existence of substantial external long-term ESS relates to a range of significant market failures. The long-term evolution of ESS is affected by many actors driven by (short-term) timebounded rationality, whilst principal-agent problems are rife. Poor consumers have a short time horizon by existential necessity. Yet many affluent consumers with much more leeway to integrate long-term consequences into their use of energy services opt for hedonic, high-environmental-externalities lifestyles. Quite a few politicians in western-style democracies are guided in their decisions and communications with their constituencies by the anticipated impact thereof on their (party's) rating in the upcoming elections rather than by long-term societal impacts. ${ }^{7}$ The ongoing credit crisis has made manifest, that prospects for short-term profits in tandem with low levels of risk aversion preferences constitute the overriding driver for decisions made in many company boardrooms. Under current institutional settings downside risks are often shifted to other stakeholders (shareholders, rank-and-file employees, customers). To take an example in the energy supply business, the 'dash for gas' in the

\footnotetext{
${ }^{7}$ For example, when in 2008 the spot price of a barrel of oil surged to levels well above 100\$US, on both sides of the Atlantic, politicians floated proposals towards oil tax reductions or chasing unscrupulous speculators on the oil futures markets suggesting that this would bring down oil prices. Another popular proposition was the introduction of additional taxes to skim "excessive profits" of large international oil companies in order to administer fuel-cost-specific subsidies to low-income families.
} 
portfolios of generating assets of many large power suppliers seems to be prompted by short-term risk management practices. In anticipation of high co-variance between natural gas and wholesale electricity prices, portfolio managers may appreciate low capital cost risk of gas-based generation while counting in the given liberalised market setting on their customers to assume the lion's share of the - especially at longer timescales - high fuel price risk.

Strong inertia exists affecting negatively the capacity to manage long-term price risks of energy carriers. Capital investments in energy production, transformation, and distribution often have gestation periods of several years and operating lifetimes spanning several decades. Decisions on investments in spatial infrastructure and housing can have lock-in effects lasting for centuries. Technology development decisions can lock in advanced technology to the detriment of, on hindsight, alternative advanced technology with better cost and environmental performance. The same goes for public spatial and infrastructural planning decisions, often locking in the use of private cars as the dominant passenger transportation mode. Besides, profligate, high-environmental-externalities lifestyles seem to be amenable to very gradual change only unless well-publicised dramatic events unfold.

The issue of international transfers of resource scarcity rents is an under-exposed, but quite significant ESS externality aspect. ${ }^{8}$ The externalities of international rent transfers do not only relate to the welfare economic impacts upon fuel-importing countries in a conventional sense. ${ }^{9}$ The accumulation of resource rents can provide ample political clout to the ruling elites in fuel-exporting countries to wield and consolidate authoritarian regimes, especially in the absence of the pre-existing checks and balances of western types of political democracy (Karl, 1997). For society at large in the fossil fuels exporting countries the net benefits record is chequered at best (Bannon and Collier, 2003; Collier, 2008). A distinction can be made between decision-making elites in a nonwesternized fuel-exporting country regarding the allocation of resource scarcity rent inflows, in short "the ruling elites", and the remaining citizens, in short "their subjects". In non-westernized fuel-exporting countries, i.e. countries with authoritarian regimes, wealth inflows tend to be used to consolidate the privileges of the ruling elites and their stranglehold on the political system, public life and media, and the economic system dominated by state monopolies. The rent transfers increase the discretion of the ruling elites to pursue socio-economically wasteful policies, such as conspicuous consumption of imported luxury but also fuel subsidies and white elephant prestige projects in a bid to appease their subjects. Besides, windfall scarcity rent inflows can provide the means to a wide variety of political gaming under the pretext of resource nationalism. At odds with assumptions underlining welfare economic theory, these games do by no means need to be in line with socio-economically rational policies from the societal perspective of fuel-exporting countries concerned (Karl, 1997). Trickles of these inflows might even be diverted to financing acts of terrorism. Moreover, the "Dutch disease" phenomenon with galloping inflation and resulting reduction in competitiveness of the non-fuel industries can bring about social unrest among the social underclass. Furthermore, state budgets of resource-rich

\footnotetext{
${ }^{8}$ Impact of oil prices on global imbalances and recycling of oil revenues are analysed in Rebucci and Spatafora (2006).

9 Welfare economists tend to focus only on that part of the rent component associated with supra-competitive prices resulting from (threats to make) use of market power by fossil fuel exporters. This leaves the large chunk of the rent component, i.e. infra-marginal rents, out of the picture, in spite of the serious socio-political impacts thereof in the exporting countries and socio-economic feedback to the importing countries.
}

countries are exposed to large volatilities in the government take of scarcity rent. In-fighting within the ruling elites for supreme power and social unrest among their subjects fed by increasing social inequity and the downturns of boom-bust cycles of global fuel markets can lead to instable political systems (e.g., Bannon and Collier, 2003). Some analysts observe that the fuel scarcity rent inflows often prove a resource curse rather than an instant recipe for acceleration of socio-economic development (Karl, 1997; Collier, 2008). The economies of many fuel exporters are performing relatively poor over longer timescales (Sachs and Warner, 1995; Karl, 1997). The feedback mechanisms of these types of socio-political impact upon fuel-importing countries are typically neglected by conventional welfare economic approaches of the impact of energy security (Bohi and Toman, 1996; Greene and Leiby, 2006; Arnold et al., 2007).

In fuel-exporting countries with a western-style political system, such as Australia, Canada, Norway and the Netherlands, the political system has relatively well-developed checks and balances to mitigate social inequity impacts upon the national population. Nonetheless, also their national economies tend to suffer from "Dutch disease" impacts and the volatility in scarcity rent revenues. Moreover, in these countries expanding resourcewealth-financed public works and welfare programmes contribute to increasing scarcities on the labour market for low-skilled jobs and the dislike for such jobs among indigenous low-skilled citizens. In the absence of migration planning (screening and quota) policies, this may trigger the immigration of low-skilled families with very different cultural and religious backgrounds. The consequential build-up of, initially latent, social tensions in cities with large cultural minorities may negatively affect living conditions of the indigenous and minorities underclass alike and, hence, social stability.

\subsection{ESS externality valuations are intrinsically subjective}

Researchers engaging in quantitative valuations of security externalities cannot avoid subjective propositions beyond the realm of positivist science. Normative aspects, such as interpretations of the affordability and environmental compatibility of the consumption of energy services as well as societal ESS risk aversion preferences, are intricately linked with assessing ESS levels and externalities.

\section{Some recent approaches to measure supply security}

\subsection{Multi-fossil-fuels energy security measurement}

In the 1990s world-wide use of natural gas, most notably in many OECD member states, has expanded rapidly. The disparate geographical distribution of natural gas resources and the specific risks pertinent to cross-border pipeline natural gas supply chains brought home the message that energy security is not only a matter of the vagaries of the world petroleum market. As from 2004, it became clear that coal-based energy services are also liable to serious risks in the coal supply chain. An additional factor prompting multi-fuel supply approaches to the 'energy security' issue is climate change. Advocates of fast policy action to address climate change sought to strengthen their case by invoking the potentially significant energy security co-benefits of climate change mitigation measures. This aroused interest in interactions of climate change and energy security policy measures.

Let us consider the perhaps most well-known recent document of a multi-fossil-fuels approach to the design of energy security 
indicators, i.e. the one proposed by the IEA (Lefèvre, 2007). ${ }^{10}$ It adheres to the rather confined welfare economics perspective and postulates that energy insecurity stems from the welfare impact of either the physical unavailability of energy, or prices that are not competitive or overly volatile. The IEA proposes:

- A composite multi-fossil-fuels index of energy security, composed of single energy security indicators based on market concentration in the international markets ( $\left.E_{\text {price }}\right)$ : for oil and gas with oil-linked pricing; gas with gas-based pricing; and coal, respectively; ${ }^{11}$

- A second energy security indicator based on physical unavailability $\left(\mathrm{ESI}_{\text {volume }}\right)$ : for gas imported through pipelines with oillinked pricing. ${ }^{12}$

The two indicators permit relative (ranking) comparisons. These enable to investigate in which direction the level of energy security of a specific country or region is projected to evolve relative to a base year under a certain scenario or whether energy security in country (region) A is less/higher than in country (region) B in a certain year. Measured (projected) values for ESI $_{\text {price }}$ or ESI $_{\text {volume }}$ or - provided resulting ranking information with the two indicators being mutually consistent - both would provide clues.

The following observations can be made on the two IEAproposed energy security indicators. As demonstrated in the country case studies, the IEA-proposed indicators of energy security can be applied in a forward-looking way indeed. This requires projections of international trade in (imports of the country/region considered of) fossil fuels, broken down by trading (export) regions or countries. Moreover, taken together the two indicators broaden the scope of energy security measurement from one to three fossil fuels. Yet the indicators still have some major flaws. Their most important limitation is that they only refer to international fossil fuel markets. By implication, they neglect other sources in the energy mix and key resilience aspects of a country's energy system, i.e. the performance of the country (region) considered itself in mitigating the potential impact of (latent) energy insecurity. Furthermore, a certain non-extreme numerical outcome as such of the Herfindhal-Hirschman Index (HHI) of market concentration, and by implication the IEAproposed energy security index, cannot be readily interpreted by less informed policymakers and other users. Besides, outcomes for both proposed indicators taken together and their mutual relationship in defining an overall energy security level is also puzzling for external observers. One index instead of two indicators makes comparisons easier and more readily communicable. Finally, in the review of indicator approaches in Annex I of

\footnotetext{
${ }^{10}$ This publication was the second major one in a multi-annual IEA research programme on energy security indicators which included five country case studies. It builds on the first major publication in this programme, (Blyth and Lefèvre, 2004), which in turn was partly based on Stirling (1999) and Jansen et al. (2004).

11 Broadly similar to a procedure proposed in Jansen et al. (2004), the initial indicators are adjusted to account for political stability in the export countries. One difference is that (Lefèvre, 2007) assumes that the future level of political stability will remain the same as the last measured level, which makes sense because of its lack of predictability. The adjustment for political stability in supplying export countries changes the range of possible outcomes from $[0$, $10,000]$ for a simple HHI with 10,000 as the least energy-secure outcome (one supplying country to the importing country considered) to $[0,30,000]$. The level of 30,000 would obtain for the case with not only extreme market concentration, i.e. one supplier; the single supplying country would also be characterised by the highest level of political instability with a value 3 on a $[1,3]$ scale.

12 This indicator has a $[0,100]$ scale, where 100 is reached when $100 \%$ of a country's total primary energy supply is met by gas imported through pipelines under long-term oil-price-indexed contracts. Gas traded "on gas-based terms" at natural gas exchanges is treated like LNG.
}

Lefèvre (2007) just one other approach is singled out for questioning the subjective arbitrariness in defining the relative importance of the different components or parameters to construct supply security indices. Yet every approach to design meaningful energy security indicators faces this problem. ${ }^{13}$ The

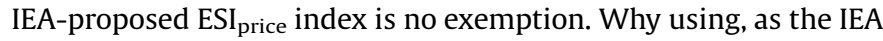
does, the share in total primary energy supply and not, for example, share in total value of primary energy supply as weight of a component indicator in the overall index? And why using an adjustment factor for the political stability of an export country on a $[1,3]$ scale and not on, for instance, a $[1,10]$ scale? Even the IEA accounting of for quantities of energy from different sources in total primary energy supply suffers from a serious "apples and oranges" aggregation problem. ${ }^{14}$ All in all, doubts remain as to whether the energy security indicators proposed in Lefèvre (2007) are indeed capable of meeting the set objective, i.e. to "focus on measuring the cause of energy insecurity". ${ }^{15}$

\subsection{Diversity-based indices}

One of the first attempts to design composite indices of energy supply security was in Jansen et al. (2004), i.e. a small pre-study to a larger one on four long-term global environmental sustainability scenarios. ${ }^{16}$ This pre-study addresses the key research question as to whether it is possible to design a composite index for long-run energy supply security and if so how. Available scenario information on the projected evolution of 17 world regions and scanty previous work on this issue formed its ingredients. The approach chosen to address the key question is prompted by work of Andrew Stirling on diversity analysis (Stirling, 1994, 1999). The basic presumption is that large blind spots of ignorance mark one's perspective of long-term future socio-economic developments. If this holds true indeed, well-designed diversity strategies hold out the best promise for energy supply security.

Four composite diversity indices of long-term energy security are introduced, allowing for successive additional integration of different supply security aspects on a stepwise basis. The indices are based on the Shannon-Wiener diversity index for application to multi-fuel energy supply security. In the last two indices the basic "total ignorance" diversity concept is merged with distinct geopolitical (indices $\left.I_{3}, I_{4}\right)$ and exhaustibility $\left(I_{4}\right)$ elements for which the total ignorance assumption is departed from and prior knowledge is presumed. The four diversity-based indices are:

- Diversification of energy sources in energy supply $\left(I_{1}\right)$.

- Diversification of imports with respect of imported energy sources $\left(I_{2}\right)$.

- Long-term political stability in regions of origin $\left(I_{3}\right)$.

- The fuel resource base in regions of origin, including the home region $\left(I_{4}\right)$.

These indicators are normalised into a $[0,100]$ scale, with a lower value indicating an inferior supply security situation.

\footnotetext{
${ }^{13}$ Stirling's most advanced diversity approach as expounded in, among others, (Stirling, 1999) might avoid this problem.

14 Segers shows that from a climate change mitigation perspective the IEA accounting rules for energy volume seriously underrate the contribution of ambient energy flow resources such as notably wind power to total energy supply (Segers, 2008)

15 (Lefèvre, 2007: p.13). Italics mode inserted by the present authors.

16 The credit for the first attempt to design a multi-fuel index goes to Thomas Neff (Neff, 1997). Through a simple HHI index (Neff, 1997) proposed to measure energy security by the level of diversification of the energy mix, comparable to index $I_{1}$ introduced immediately hereafter in the main text. No other energy security aspects were included in the energy security index proposed in Neff's quoted publication.
} 
The proposed four diversity-based indices are applied to longterm scenarios on the global energy and sustainability evolution with year 2030 as time horizon and 1995 as base year. The longterm scenarios are further explained in Mooij and Tang (2003). The four proposed indices indicate for each scenario a clear but divergent tendency towards reduced energy supply security over time for the OECD Europe region. ${ }^{17}$

When reliance has to be had on pre-set sustainability scenarios and a long-term time horizon, in the face of huge uncertainties Stirling's diversity approach has strong merits. Moreover, this approach is simple in principle and can be readily communicated. A weak point, though, of the pure diversity approach as such is the equal treatment of all sources, assuming complete ignorance. Yet for certain aspects we do have meaningful prior knowledge. For example, we know that certain sources are exhaustible whereas others are not. Index $I_{4}$ addresses this issue to a certain extent. A second major weak point is the absence of any feedback mechanism on the demand side. It can be expected that once the message gets across of increasing risks that events of major supply vulnerabilities will become manifest, actors in the home region will go for remedial public measures and private actions to mitigate such risks. The demand-side resilience is not accounted for in any of the aforementioned diversity-based indices.

\subsection{Supply/Demand Index}

The resilience of a certain society against shocks in the supply of energy resources driving the provision of societal needs for energy services is not only determined by diversification of notably external - supply and other non-domestic supply considerations. The structure and intensity of national (regional) demand for energy services, supply elasticity for distinct categories of energy services, the inland supply chain and conversion infrastructure and the physical environment affecting societal needs for fuels and electricity are part and parcel of the supply security equation as well. Some recent approaches towards designing supply security indicators include inland infrastructural and demand-oriented aspects as well. Hereafter we explain the Supply/Demand Index ( $S / D$ Index), proposed by Energy research Centre of the Netherlands, ECN, and the Clingendael International Energy Programme, CIEP, (Scheepers et al., 2006, 2007).

The $S / D$ Index is a supply security indicator for a defined region in the medium and long run that sets out to integrate major underlying supply-side and demand-side factors. This index is normalised to range from 0 (extremely low security) to 100 (extremely high security). It covers final energy demand, energy conversion and transport and primary energy sources supply and, hence, in principle the entire energy system. The $S / D$ Index uses four types of inputs, two objective types and another two of a more subjective nature. The more or less objective inputs concern the shares of different supply and demand categories (i.e. for supply: oil, gas, coal, nuclear, RES and other; for demand: industrial use, residential use, tertiary use and transport use) and the values characterizing efficiency, adequacy, and reliability in conversion and transport based on the secondary energy carriers (electricity, gas, ${ }^{18}$ heat, and transport fuels). Fig. 1 displays the conceptual model of the elements considered in the overall $S / D$ Index.

The subjective inputs concern the weights that determine the relative contribution of the different components in the $S / D$ Index (such as the relation between supply and demand outputs in the

\footnotetext{
${ }^{17}$ See Jansen et al. (2004) for further details.

18 The updated S/D Index model (Scheepers et al., 2007) has a separate branch for the secondary energy carrier gas.
}

Index, or the relation between EU imports and non-EU imports) and the scoring rules for determining various $S / D$ Index values reflecting different degrees of perceived vulnerabilities. Currently, the $S / D$ Index is officially adopted by Ireland (SEI, 2006, 2007) and the Netherlands. Recently, the IEA Clean Coal Centre used the $S / D$ Index to assess the role of coal and energy security (Kessels et al., 2008).

The use of the $S / D$ Index can be illustrated with examples for the EU-27 and its member states for the years 2005 and 2020. The examples are based largely on information contained in energy balances, derived from mainly Eurostat (Eurostat, 2006) and IEA statistics (IEA, 2006) and the 'EU Trends to 2030-update 2005' baseline scenario (EC, 2006b). The $S / D$ Index model combines that information with certain default weighing factors and scoring rules. $S / D$ Index values for the year 2005 are displayed in Fig. 2.

The un-weighted average of the $S / D$ Index values for the $27 \mathrm{EU}$ member states in 2005 is about 56. The range is from 25 (Cyprus) to 82 (Denmark). The primary underlying factor accounting for the differences in scores between EU member states consists of differences in the primary energy sources sub-index. ${ }^{19}$ Member states with high import dependencies for oil and gas, combined with high shares of these imports originating from outside the EU/Norway, have a relatively low score. Such member states include: Cyprus, Luxembourg, Malta, Latvia, Greece, Lithuania and Portugal. On the other hand, member states that are net exporters of gas and/or oil mark a relatively high score, i.e. an S/D Index of 60 or higher, for example the United Kingdom anno 2005 (80). Member states that import oil and natural gas mainly from within EU/Norway and/or deploy renewables and/or combined heat and power abundantly also achieve relatively high $S / D$ Index values. Examples are Denmark (82), Ireland (75), and to a lesser extent Sweden (70). As most of the larger member states (Germany, France, United Kingdom) exhibit relatively high scores, the score for the whole EU-27 region is also relatively high (65).

Projections of $S / D$ Index values in year 2020 for EU member states suggest some noteworthy upcoming developments. ${ }^{20}$ The overall supply security level in the EU is poised to decrease. For example, for Ireland and the UK a quite large decrease in energy supply security as captured by the $S / D$ Index is projected, as a surge in sourcing of primary energy sources outside the EU/Norway is envisaged for these countries.

Projections of future $S / D$ Index values are highly scenario dependent. This is brought out by Fig. 3 showing relative changes in the projected $S / D$ Index score for the EU-27 in 2020 under five PRIMES alternative policy scenarios (EC, 2006c), taking the PRIMES baseline scenario as the reference (EC, 2006b). These are coupled with corresponding changes in $\mathrm{CO}_{2}$ emission levels to gauge possible synergies in energy supply security and GHG abatement policies. The combined energy efficiency (EE) and HIRES (high, i.e. 20\%, renewables) scenario gives the best results in terms of energy supply security improvement and $\mathrm{CO}_{2}$ emissions reduction. Emissions in the EU in 2020 under EE_HIRES $\mathrm{CO}_{2}$ are projected to be $25 \%$ less than under the baseline scenario, whilst the supply security scores as captured by the $S / D$ Index is projected to be $12 \%$ higher.

A major advantage of the $S / D$ Index compared to most alternative measures would seem to be its relative comprehensiveness with the inclusion of some important demand-side aspects. The necessary corollary of comprehensiveness is reduced simplicity. On the other hand, for long-term security purposes in the primary energy supply the geopolitical-political dimension is

\footnotetext{
${ }^{19}$ See for example Scheepers et al. (2007) for details on sub-indices such as the PES sub-index.

${ }^{20}$ See Scheepers et al. (2007) for more details.
} 


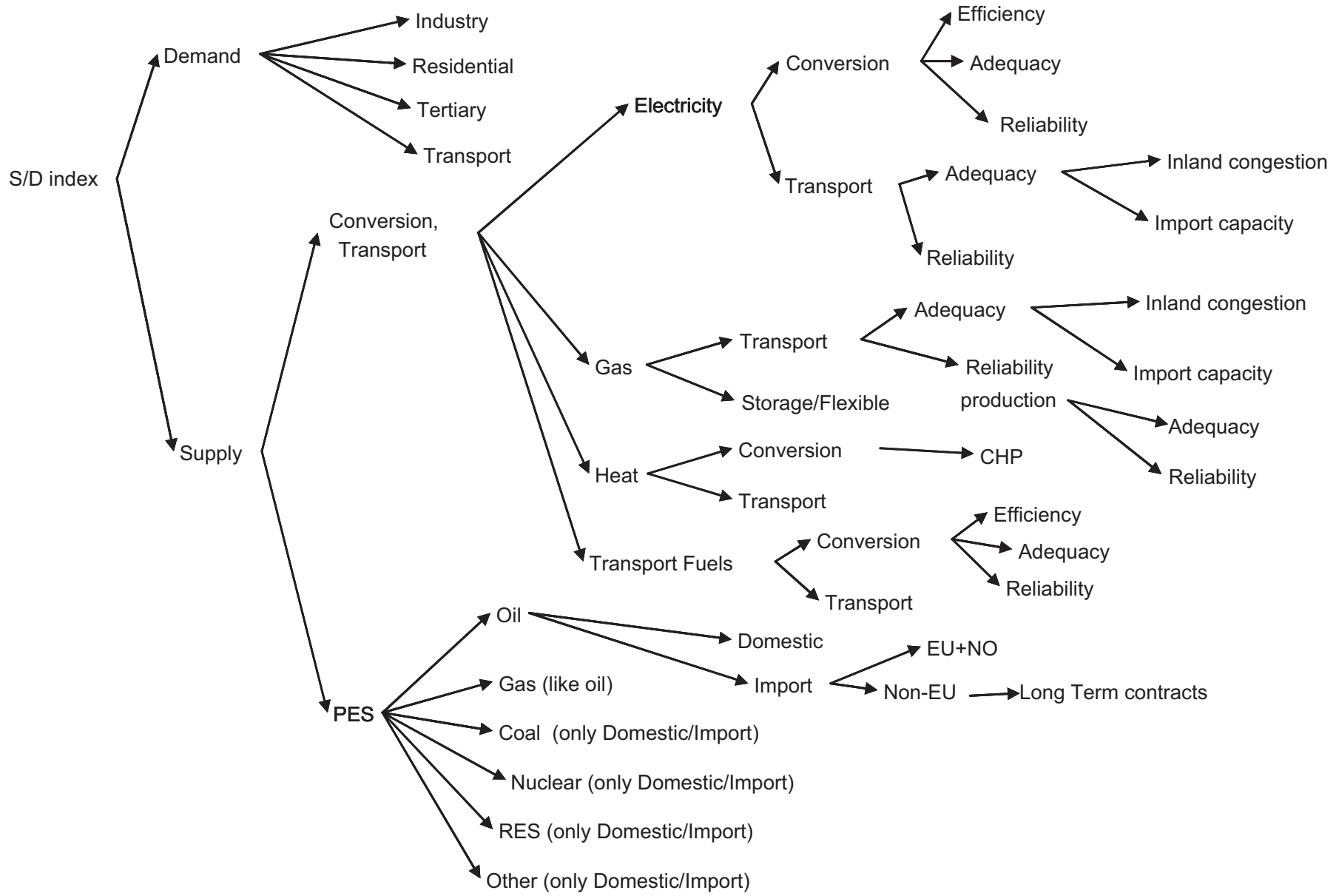

Fig. 1. The Supply/Demand Index model structure.

captured less well, compared to e.g. the diversity-based indices set out above. Furthermore, aggregation of the various components entails some subjective value assignments. These can be set in consultation with, and allowing for preferences of, users including policy makers.

\section{Recent valuations of supply security externalities}

So far, fairly few attempts have been made to gauge - in a quantitative fashion - the hazards of vulnerable fossil fuel markets and the resilience of an economy to cope with price volatilities of fossil fuels. The first treatises on the measurement of energy security or its externality valuation relate to the vagaries of the world oil market. With the ascent of natural gas and the price mitigating role that coal could possibly play, the focus of attention has recently expanded to multi-fossil-fuels approaches. In this section some examples of such approaches are reviewed.

\subsection{Energy security externality valuation focusing on oil}

In the 1970s and early 1980s two brief periods of oil availability uncertainty and related hefty oil price shocks occurred, following the Arab-Israeli Yom Kippur war and the announcement of the Arab oil embargo in 1973 and the Iranian revolution in 1979, respectively. These oil price shocks took the western economies by surprise and set 'energy security' on the political agenda. For instance, in 1974 the International Energy Agency, IEA, was established as a special apex organisation of the OECD in Paris.
The IEA was to promote co-operation among the oil-importing member states of the OECD in situations of a tight global oil market and was initially intended to act as a countervailing organisation to the Organisation of Oil Exporting Countries, OPEC, in Vienna.

Initially most quantitatively oriented energy security analyses focusing on oil set out to stylise the global oil market as a market dominated by the OPEC cartel. The main question to address was whether public interventions were warranted on the part of oilimporting countries to maximise economic welfare in the latter countries. If the answer was positive, the optimal type and magnitude of such interventions were to be determined. Typically, analysis was conducted to construct oil market models from a welfare economics perspective, based on static or dynamic partial oil market equilibrium modelling. Parameter values tended to be quantified in a backward looking way under the tacit premise that the past is a good predictor of the future. Douglas Bohi and Michael Toman provide more background to this approach (Bohi and Toman, 1996).

Bohi and Toman associate the concept of 'energy security' with 'the loss of economic welfare that may occur as a result of a change in the price or availability of energy'. They seek to design an approach to quantify 'meaningful forms' of energy security externality. An externality refers to the spill-over effects (costs or benefits) of one person's activities to another person's welfare. According to Bohi and Toman (1996), it makes no sense to include externalities 'for which no cost-effective policy options are currently available' in an exercise that determines government policy. Only 'policy-relevant externalities' should be considered. 


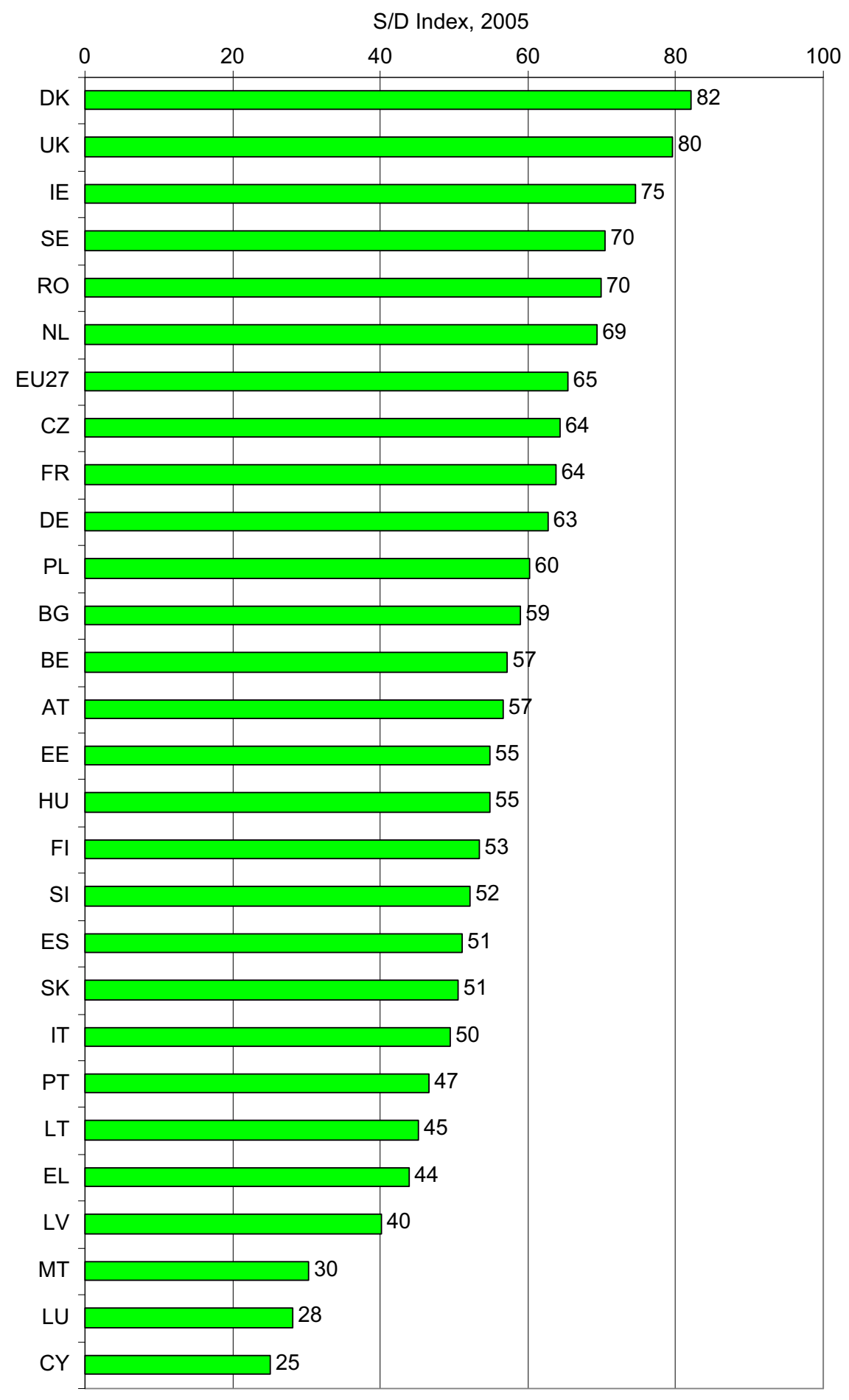

Fig. 2. S/D Index, EU-27 and Member States, 2005, PRIMES based.

Based on reasoning from a restricted welfare economics perspective Bohi and Toman (1996) conclude that the - even conceptual - case for significant energy security externalities 'is weaker than much of the literature would suggest'. They do not account for any energy security externality as this would not be meaningful in view of major analytical uncertainties. In arriving at this conclusion, Bohi and Toman (1996) would seem to fall short of making (due) allowance for the looming long-term political, social, environmental and consequential socio-economic security challenges. Nor do they duly allow for the external benefits associated with the potentially fast technology dynamics of potentially successful sustainable energy technology.

A similar, but much more robust, approach is presented by David Greene and Paul Leiby in a report describing methods for projecting the prospective energy supply security benefits for the US of advanced technologies, such as Advanced Hybrid Technology for Light-Duty Vehicles (Greene and Leiby, 2006). Both monetary and non-monetary metrics of energy security are calculated. The principle monetary metric is based on comparing 


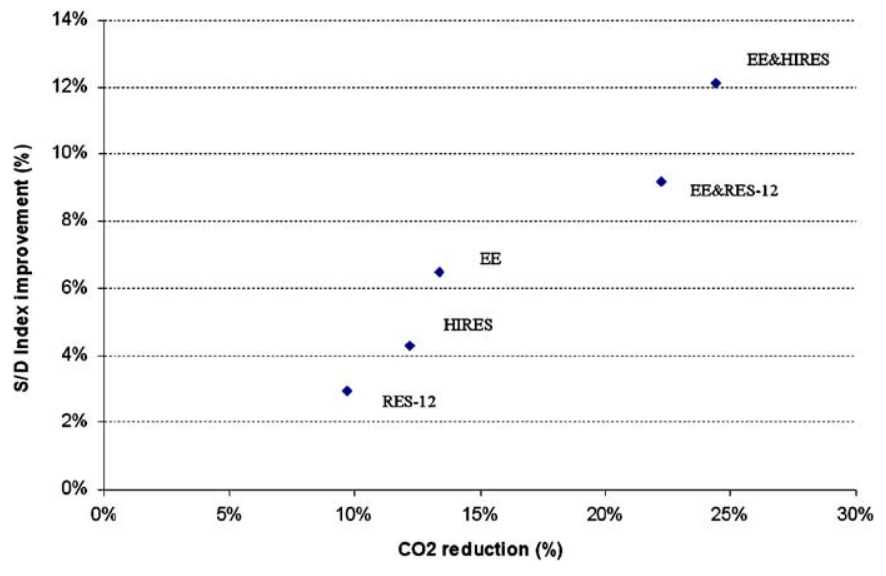

Fig. 3. Projected relative change in $S / D$ Index 2020 and in $\mathrm{CO}_{2}$ emissions under five PRIMES alternative policy scenarios as compared to the baseline scenario.

the combined costs under "normal" (undisrupted) global oil market conditions to those under disrupted market conditions of:

(1) wealth transfer from the US economy to oil exporting economies,

(2) potential GDP loss, i.e. producers' and consumers' surplus losses as a result of higher oil prices, and

(3) macro-economic disruption losses resulting from oil price shocks.

Their Oil Security Metrics Model (OSMM) is applied in a forward-looking way based on projections from official scenario studies by the Energy Information Administration (EIA), coupled with two alternative OPEC market supply strategies. These rather extreme OPEC strategy simulations, i.e. no volume change with respect to the baseline as against supply reduction to maintain the baseline target price, help to provide indications of the bandwidth of energy security benefits under a variety of simulated OPEC market responses. The OSMM approach and its elaboration by Greene and Leiby (2006) is analytically attractive. Its results are contingent on the official EIA scenarios, which to our judgment might err - not unlike most other official scenarios ${ }^{21}$ - on the high side regarding long-term fuel availability and hence might underestimate the associated upward price risk. Furthermore, also the OSMM approach refrains from including feedback mechanisms from the socio-economic fall-out from social disruption in fuel-exporting countries upon fuel importers, such as notably the US.

Welfare economic approaches neglecting or flatly discarding normative issues such as the value of long-term socio-political ESS externalities are by no means a recipe for sheer positivist, valueneutral knowledge of the issues at stake. Rather such approaches tend to yield results that implicitly incorporate quite extreme judgments suggesting that the social value of such externalities would be very low or even negligible. ${ }^{22}$

\footnotetext{
${ }^{21}$ We observe a rather consistent tendency regarding official scenarios to assume an extrapolation of stable or gently rising real fossil fuel prices starting out from averaged-out recent price data. Consequently, except for brief spells of hefty price spikes, e.g. after the Iranian revolution of 1979, official scenarios would tend to err on the low side on future price projections. (Jansen et al., 1996; Bolinger et al., 2006).

22 E.g. Bohi and Toman (1996); Arnold et al. (2007).
}

\section{Concluding remarks}

\subsection{The need for an integrated approach}

This paper has reviewed some approaches to quantify levels and externalities concerning services security with special reference to the European Union. The key message is that an integrated approach is needed that starts out to map, and analyses how to meet, the requirements of end-use energy services from the vantage point of the end users in the long run on a sustained basis. Approaches focusing on 'energy security' tend to be too narrow in scope for capturing all key issues at stake. The definition of 'energy' in 'energy security' - although from a physics perspective invariably incorrect - varies among the different energy security approaches. These approaches tend to underexpose essential aspects for resilience performance to address energy services security on the demand side, such as energy efficiency and underlying aspects such as spatial and infrastructure planning and consumption patterns. Also the socioeconomic feedback mechanisms from the politics and consequential social inequity of resource rent transfers to exporting countries of fossil fuels deserve special attention.

\subsection{Valuation of supply security externalities}

Fossil fuels have a range of negative externalities, including carbon emissions, local pollutants emissions and ESS-related ones. In the US (on local pollutant emissions) and Europe (on carbon and local pollutant emissions) market-based and command-andcontrol policies have been designed and implemented towards a politically agreed extent of internalisation of non-ESS externalities. However, policies towards internalisation of ESS externalities in the use of fossil fuels is still in its infancy, whereas it was set out above that such policies are urgently needed from various perspectives.

No positivist, objective approach exists to quantitatively project the external security cost in a robust way. We, therefore, recommend the institution of a consultative process towards broadly accepted assignment of fuel-specific ESS premiums on the use of fossil fuels to foster integration of long-term ESS concerns in

- social cost-benefit analysis of policy measures and public spending and

- taxation of fossil fuels.

The initiation of a consultative process bringing together public policy officers, stakeholder representatives, and researchers of energy services security to exchange information and views on the ESS valuation issue. This process can be implemented at national level and, for instance EU-wide, at regional level. Recently, the European Commission has instituted a bi-annual strategic energy review procedure (European Commission, 2006a). It would seem in order that such a review will include consultations on the state of long-term energy services security across the EU and its member states, key EES enhancing projects and policies, and integration of ESS externalities in European energy markets.

Making explicit allowance for, notably long-term, energy services security externalities associated with the use of fossil fuels should be standard practice in social cost-benefit analyses. Recently, a fairly simple approach was suggested to incorporate inter-subjective externalities in terms of fossil fuel premiums to be determined in consultation with stakeholders such as government policy assessment agencies (Jansen and Bakker, 2006; 
Egenhofer et al., 2006). A much more complex approach predicated on the same basic idea is proposed by Bollen (Bollen, 2008).

\subsection{Measures enhancing long-term ESS}

From a supply security perspective, major importing states or regions of fossil fuels, such the $\mathrm{EU}$, have compelling reasons to go for a strong and sustained policy intensification to reduce the dependency of their economy on fossil fuels. Yet most official policies undertaken to promote 'energy security' focus on shortterm policy measures such as strategic reserves, gas storage, creating more supply flexibilities e.g. supply diversification and infrastructural redundancies such as building of LNG import terminals. At best, better fuel economy and fuel savings at the consumer end is promoted (without putting mandatory energy efficiency targets in place).

Whilst underscoring the great importance of such measures, much more needs to be done to wean our economy from its addiction of fossil fuels. A more systematic approach to foster substitution towards renewable fuels and behavioural change away from excessive high-externality consumption patterns is warranted.

Just a few key observations on reducing our dependence on fossil fuels are the following. The electricity supply system brings user convenience, can absorb virtually any source of energy among which notably ambient sources - and can be transported relatively cheap over large distances. This makes electricity the key energy carrier to improve the ESS performance of our energy economy. Further electrification of our energy system, greening our electricity system, as well as improving capacities, energydensities and cost performance of electricity storage devices are imperatives to achieve long-term ESS. Further electrification enhances the flexibility in the use of primary energy resources to meet our needs for energy services and the scope for deployment of renewable sources. ${ }^{23}$

In the drive towards an 'electricity economy' land transportation appears a very promising application area in the medium term. Electrification of passenger transport vehicles appears to be a major potential contributor to the phasing-out of oil and improving energy efficiency. It remains to be seen whether second or third generation biofuel or hydrogen-based storage devices will also play a major role in road transportation and facilitating the use of intermittent ambient energy to generate power (King, 2007; Carson and Vaitheeswaran, 2007). Currently, the case for hybrid and battery electric vehicles seems to gain in strength as battery technology advances. Diversification of RD\&D in the face of ignorance seems in order. Lock-in of possibly higher cost hydrogen-based transportation should be avoided (Kendall, 2008). Currently, in support to the use of bio-energy, the emphasis is put on road transportation (e.g IEA, 2008). Given constraints to the supply of sustainable biomass at least a partial re-allocation of public RD\&D and market stimulation efforts into 'niche' directions where the scope for electrification of energy services is limited. These might include biofuels for maritime and air transportation, certain heat applications and non-energy industrial feedstocks. Not unlike the hydrogen lobby, the lobby in favour of carbon capture and storage (CCS) is strong as well. Yet this option is clearly at odds with enhancing energy efficiency and long-term ESS. The long-term ESS is a lesser drawback for

\footnotetext{
${ }^{23}$ Markowitz's mean-variance portfolio theory can be fruitfully applied to portfolios of generating assets as an alternative approach to quantify overall risk to electricity-based energy services security. See among others: Bazilian and Roques (2008), Awerbuch and Berger (2003), Grubb et al. (2006), and Jansen and Beurskens (2008).
}

countries with large inland coal reserves, such as the US, China and India. Given the urgency to address the climate change problem, international CCS technology development co-operation between these countries is warranted (Klare, 2008; IEA, 2008). Yet crowding out public RD\&D resources to the detriment of RD\&D for enhancing energy efficiency and substitution of fossil fuels is to be avoided, especially by countries and regions with an increasing coal import dependency such as the EU.

Furthermore, a multitude of options for demand reduction include explicitly behavioural changes and sustainability-oriented spatial planning in combination with public investment in mass transit infrastructure. Stronger push and pull measures might need to be implemented to bring about behavioural changes away from high-environmental-externalities activities than sheer market-based incentives.

\subsection{Advancing the design of credible long-term ESS indices}

It has been explained at length above that long-term ESS security is not only determined by the evolution of security vulnerability with respect to specific energy sources; also demand-side resilience performance to address it matters a great deal. The index should benchmark on the demand side end-use sectors on characteristics such as energy-efficiency performance - including inland transformation and distribution losses of energy carriers up to the consumer's doorstep - and performance regarding the phase-out of fossil fuels. Energy efficiency performance in energy end-use sectors and energy conversion and transportation is of key importance. Furthermore, the share of non-fossil fuel sources and flexible energy carriers (electricity) in the final energy use mix should be notably given weight in end-use sectors with poor short-term substitution opportunities such as transportation. Also, the shares of non-fossil fuel and distributed energy resources in the power sector are key parameters in defining the societal resilience in the face of external fossil fuel supply vulnerability.

As explained above, a growing economic role of resource rents is a major factor contributing to long-run risks to energy services security. Future work on EES indices is to incorporate this aspect. Furthermore, diversity in terms of foreign sources and independent transport routes are key. E.g., the Nord Stream gas pipeline certainly has value for improving energy services security in the EU. Yet the Nabucco project would add more (Müller-Kraenner, 2007).

A final remark concerns statistical units of account for energy. From the perspective of fossil fuels related supply security issues the energy accounting systems used by the IEA and the European Commission do seriously underreport the role of ambient energy resources in the energy mix (Segers, 2008). It is proposed to include a simple substitution method, as proposed by Reinoud Segers to establish energy mix weights in primary energy supply and final use.

\section{References}

Arnold, S., Hunt. A., Markandya, A., 2007. National and EU level estimates of energy supply externalities. Deliverable D.5.1, Section 1 of CASES project of EU FP6. University of Bath. Bath, UK.

Awerbuch, S., Berger, M., 2003. EU Energy Diversity and Security: applying Portfolio Theory to Electricity Planning and Policy-Making. International Energy Agency, Paris.

Bannon, I., Collier, P. (Eds.), 2003. Natural Resources and Violent Conflict: Options and Actions. World Bank, Washington DC.

Bazilian, M., Roques, F. (Eds.), 2008. Analytical Methods for Energy Diversity and Security; A Tribute to Shimon Awerbuch. Elsevier, Oxford/Amsterdam.

Bohi, D.R., Toman, M.A., 1996. The Economics of Energy Supply Security. Kluwer, Norwell, USA 
Bolinger, M., Wiser, M., Golove, M., 2006. Accounting for fuel price risk when comparing renewable to gas-fired generation: the role of forward natural gas prices. Energy Policy 34, 706-720.

Bollen, J., 2008. Energy security, air pollution, and climate change: an integrated cost-benefit approach. MNP report, Bilthoven. Available at <http://www. nmp.nl $>$.

Blyth, W., Lefèvre, N., 2004. Energy Security and Climate Change; An Assessment Framework. OECD/International Energy Agency, Paris.

Carson, I., Vaitheeswaran, V.V., 2007. ZOOM: The Global Race to Fuel the Car of the Future. Hachette Book Group, USA, New York.

Collier, P., 2008. The Bottom Billion; Why the Poorest Countries Are Failing and What Can Be Done About It. Oxford University Press, New York

Egenhofer, C., Jansen, J.C., Bakker, S.J.A., Jussila Hammes, J. 2006. Revisiting EU Policy Options for Tackling Climate Change. ISBN 978-92-9079-631-2. Centre for European Policy Studies, Brussels.

European Commission, 2006a. A European strategy for sustainable, competitive and secure energy. $\operatorname{COM}(2006) 105$ final, 8 March 2006, Brussels.

European Commission, 2006b. European Energy and Transport Trends to 2030update 2005. European Commission, Directorate-General for Energy and Transport, ISBN 92-79-02305-5, Office for Official Publications of the European Communities, Luxembourg, May 2006.

EC, 2006c. European Energy and Transport Scenarios on energy efficiency and renewables. European Commission, Directorate-General for Energy and Transport, ISBN 92-79-02652, Office for Official Publications of the European Communities, Luxembourg, July 2006.

Eurostat, 2006. Energy and Transport in Figures-Statistical pocketbook 2005 ISBN 92-79-00569-3, Directorate-General for Energy and Transport, Office for Official Publications of the European Communities, Luxembourg, or Excel files downloadable from 〈http://epp.eurostat.cec.eu.int/ >.

Greene, D.L., Leiby, P.N., 2006. The Oil Security Metrics Model. Oak Ridge National Laboratory, Oak Ridge, Tennessee (March).

Grubb, M., Butler, L., Twomey, P., 2006. Diversity and security in UK electricity generation: the influence of low-carbon objectives. Energy Policy 34, 4050-4062.

IEA, 2006. Natural Gas Information 2006-with 2005 data. International Energy Agency, OECD/IEA, IEA Publications, Paris.

IEA, 2007. Key World Energy Statistics 2007. OECD/International Energy Agency, Paris.

IEA, 2008. Energy Technology Perspectives 2008; Scenarios and Strategies to 2050. OECD/International Energy Agency, Paris.

Jansen, J.C., Lako P., Mansvelt Beck, F.W., van der Linden, N.J., 1996. Long term prospects for fossil fuel prices. Report ECN-C-95-046, ECN, Petten, March 1996, Available at: 〈http://www.ecn.nl/ 〉.

Jansen, J.C., van Arkel, W.G., Boots, M.G., 2004. Designing indicators of long-term energy supply security, Report ECN-C - 04-007, ECN, Petten, December 2006

Jansen, J.C., Beurskens, L., 2008. Portfolio analysis of the future Dutch generating mix. In: Bazilian, M., Roques, F. (Eds.), Analytical Methods for Energy Diversity \& Security; A Tribute to Shimon Awerbuch. Elsevier, Oxford, Amsterdam.

Jansen, J.C., Bakker, S.J.A., 2006. Social cost-benefit analysis of climate change mitigation options in a European context, Report ECN-E-06-059, ECN, Petten, December 2006.

Karl, T.K., 1997. The Paradox of the Plenty; Oil Booms and the Petro-States. University of California Press, Berkeley, Los Angeles, London.
Kessels, J., Bakker, S., Wetzelaer, B., 2008. Energy security and the role of coal, Report CCC/131, IEA Clean Coal Centre and ECN, ISBN 978-92-9029-450-4 February 2008

Kendall, G., 2008. Plugged in; The end of the oil age. WWF (World Wide Fund for Nature). Brussels

King, J., 2007. The King Review of low-carbon cars; Part I: the potential for $\mathrm{CO}_{2}$ reduction. Office of Public Sector Information. Norwich, UK. Available at: $\langle$ hm-treasury.gov.uk/king $\rangle$.

Klare, M.T., 2008. Rising Powers Shrinking Planet; The New Geopolitics of Energy. Metropolitain Books, New York.

Lefèvre, N., 2007. Security and Climate Policy; Assessing Interactions. OECD/ International Energy Agency, Paris.

de Mooij, R., Tang, P., 2003. Four futures of Europe. CPB (Netherlands Bureau for Economic Policy Analysis). Den Haag. October.

Müller-Kraenner, S., 2007. Energy Security; Re-Measuring the World. Earthscan, London, Sterling (VA)

Neff, T.L., 1997. Improving energy security in Pacific Asia: diversification and risk reduction for fossil and nuclear fuels. Report commissioned by the Pacific Asia Regional Energy Security (PARES) Project, December 1997.

Patterson, W., 2007. Keeping the Lights On; Towards Sustainable Electricity. Earthscan, London.

Percebois, J., 2006. Dependance et vulnerabilite: Deux façons connexes mais differentes d'aborder les risques énergetiques. CREDEN, Universite de Montpellier, France.

Rebucci, A., N. Spatafora, 2006. Oil Prices and Global Imbalances. IMF World Economic Outlook April 2006, pp. 71-96. Washington DC: IMF. 〈http:// www.imf.org/external/pubs/ft/weo/2006/01/pdf/c2.pdf >

Sachs J.D., Warner A.M., 1995. Natural Resource Abundance and Economic Growth NBER Working Paper 5398. January 1995.

Scheepers, M.J.J., Seebregts, A.J., De Jong, J.J., Maters, J.M. 2006. EU standards for energy security of supply. ECN-C_-06-039, June 2006, Energy research Centre of the Netherlands and Clingendael International Energy Program, Petten/ Amsterdam/The Hague.

Scheepers, M.J.J. Seebregts, A.J., De Jong, J.J., Maters, J.M., 2007. EU standards for energy security of supply-updates on the crisis capability index and the Supply/Demand Index. Quantification for EU-27. ECN-E-07-004 April 2007. Energy research Centre of the Netherlands and Clingendae International Energy Program, Petten/Amsterdam/ The Hague. <www.ecn.nl/ en/ps/research-programme/energy-supply/security-of-supply-sos/supplydemandindex/ $>$.

Segers, R., 2008. Three options to calculate the percentage renewable energy: an example for a EU policy debate. Energy Policy 36, 3243-3248.

SEI, 2006. Security of Supply in Ireland 2006, Sustainable Energy Ireland, Energy Policy Statistical Support Unit, Dublin, December 2006.

SEI, 2007. Security of Supply in Ireland 2007, Sustainable Energy Ireland, Energy Policy Statistical Support Unit, Dublin, November 2007.

Stern, J., 2002. Security of European natural gas supplies. Royal Institute of International Affairs. July 2002.

Stirling, A., 1994. Diversity and ignorance in electricity supply investment Addressing the solution rather than the problem. Energy Policy 22, 195-216.

Stirling, A., 1999. On the Economics and Analysis of Diversity. SPRU Electronic Working Paper Series. Paper No. 28. 